\title{
Monitoring Older Adults' Health Information Using Mobile Technology: A Systematic Literature Review ${ }^{\dagger}$
}

\author{
Gabriela Cajamarca ${ }^{1, \ddagger(D)}$, Valeria Herskovic $1, *, \pm(D)$ and Pedro O. Rossel ${ }^{2,3, \ddagger(D)}$ \\ 1 Department of Computer Science, Pontificia Universidad Católica de Chile, 7820436 Santiago, Chile; \\ mgcajamarca@uc.cl \\ 2 Department of Computer Science, Universidad Católica de la Santísima Concepción, \\ 4090541 Concepción, Chile; prossel@ucsc.cl \\ 3 Centro de Investigación en Biodiversidad y Ambientes Sustentables (CIBAS), Universidad Católica de la \\ Santísima Concepción, 4090541 Concepción, Chile \\ * Correspondence: vherskov@ing.puc.cl; Tel.: +562-2354-7599 \\ + Presented at the 13 th International Conference on Ubiquitous Computing and Ambient Intelligence \\ UCAmI 2019, Toledo, Spain, 2-5 December 2019. \\ $\ddagger$ These authors contributed equally to this work.
}

Published: 21 November 2019

\begin{abstract}
Mobile health technologies are becoming more common to assist older people in independent living and self-management of illnesses. Although many mobile health technologies can be beneficial to older users, there remains a dearth of evidence-informed guidance to develop such technologies. The objective of this study was to conduct a systematic review to (1) determine which types of mobile health technologies have been used to monitor health in older adults, (2) determine whether these devices allow older users to visualize their data and to complement automatically gathered sensor information with subjective information or data from other sources, and (3) determine which health information about older adults is usually monitored. We performed a focused systematic literature review of the ACM Digital Library database, including papers specifically assessing the implementation of mobile health technologies (e.g., wearables), and other mobile computerized equipment for independent older adults. Our results show that the most commonly used device is the smartphone, that the monitored data is usually acceleration, heart rate and position, and that only $30.4 \%$ of studies evaluate devices for older adults with older adult participants.
\end{abstract}

Keywords: mHealth; monitoring; mobile; wearable; sensor; health; older

\section{Introduction}

Mobile technology innovations have radically altered the way we live [1]. The ubiquity of mobile technologies has made it possible to deliver health interventions through them, e.g., enabling patients to manage their health, communicate with health care providers, schedule appointments, and access health information [2,3]. Older adults, especially, are a group of users who could benefit from the use of these interventions, as they are more likely to have chronic health conditions [4,5].

Older adults are a heterogeneous group with a wide range of skills and experience with technology [6]. This may be especially true when comparing older users from different cultures or countries, e.g., in Turkey, more than 70\% of 55-65 year olds have little or no computer experience, while in countries such as New Zealand, England or the United States, this figure is lower than $20 \%$ [7]. While a literature review demonstrated the interest and intent of older people to use mobile technologies (e.g., iPhone or digital pen) [8], some studies have found that older adults use technology less than other segments of the population [9], perhaps because they have little experience with it or lack the necessary equipment [10]. A lack of familiarity in technology use may produce anxiety [11]. 
Some older adults have been found to feel fear of using technology, have a negative attitude towards it, a feeling that they are too old to learn how to use it, a lack of knowledge/experience, and linguistic problems, especially when English is their second language [12]. Since aging may be associated with a progressive decrease of intellectual, physical and psychological capacity [13], many older adults experience difficulties and/or limitations in their daily life activities and begin to depend on others. These physical restrictions (e.g., difficulty in using fingers, vision problems) also affect technology use and developers should take these characteristics into account when designing systems for older users [12].

Researchers have studied mobile health technologies for older adults, especially those with cardiovascular disease. A recent literature review identified that the most commonly used technologies in cardiovascular disease monitoring are mobile apps, and that these applications are mostly used for blood pressure monitoring, cardiac rehabilitation, arrhythmia monitoring, medication management and social support [14]. Recently, several mobile health technologies (mHealth) have emerged with the aim of providing innovative and efficient ways to help older adults in their daily lives and to reduce the cost of health care [15,16], e.g., monitoring vital functions and disease patterns [17], detecting falls or changes in motion patterns or routines $[18,19]$ or informing health care professionals of patients' health status [20]. Digital health information can be used to evaluate health anomalies and for early detection of certain chronic diseases such as Parkinson's or spinal pain [21].

Despite their advantages, the current literature supporting the use of mHealth for older adults primarily includes pilot or feasibility studies [3] that have been evaluated with young people [22]. Long-term trials and information on best practices for the design, implementation, and evaluation with older adults of such technology are limited. Furthermore, it is not clear exactly which information should be monitored, and whether the proposed technologies allow older adults themselves to use the gathered information, e.g., through visualizations or through the possibility of adding subjective information to the monitored data.

In this systematic literature review, we identify the types of mobile technologies that are designed to monitor the health of older people in their daily lives. Then we analyze whether these technologies include functions of self-reporting and visualization of health data. The main goal of this review is to understand the current practices, state of knowledge, and evidence to inform future directions about mobile health technologies for older adults.

The remainder of the study is structured as follows. Section 2 defines the relevant terms for our literature review. Then, Section 3 describes the methodology chosen for this study, including the research questions, search strategy, selection criteria, and data extraction. Section 4 presents the results. Then, we discuss our findings and present our conclusions.

\section{Background}

In this section, we review some concepts about health monitoring using self-reporting and data visualization specifically for older adults.

\subsection{Self-Reporting}

Data acquisition by self-report could complement data monitored from the patient's environment, e.g., by recording subjective patient characteristics, health behavior, functional or emotional status. In fact, self-reporting by older adults compares favorably with medical record report [23,24]. Although self-reported data may be subject to error as a result of a variety of factors, including memory, knowledge, and patient awareness [25,26], it may provide an important source of data from the patient's point of view, information that sensors or medical history may not include. For example, the monitoring of emotions and self-reporting of pain intensity could allow health professionals to improve patient treatments and understand their patients in real contexts [27]. 


\subsection{Data Visualization}

Visualization of data connects monitoring technology with the real world, representing data in a simple way, promoting knowledge and discovery, as well as improving user experience and interactions [28]. Several health data visualization systems based on the needs of older adults have been designed - e.g., focused on sleep quality, diet, physical activity, mental health, medication adherence, as well as for the management of major conditions such as cardiovascular disease and diabetes [29-34]. Designing appropriate visualizations has proven to be a challenge, especially if different stakeholders have different information needs. For example, older adults have different information needs regarding health care providers [35]. Older adults prefer to visualize data over a monthly or annual time period to detect patterns with greater clarity [29] while health care providers indicate the need to have broad-level information views and at the same time allow visualization of detailed information [35]. The development of health monitoring tools must recognize these differences in order to reconcile the needs of the users with those of the health care providers. In this sense, more knowledge of the needs of older users is required along with clear guidelines on how to address these needs.

\section{Systematic Literature Review Methodology}

\subsection{Literature Review Methodology}

To classify, assess and interpret the existing empirical studies we followed a set of guidelines [36], and defined our research questions using the population, intervention, comparison, outcome and context (PICOC) structure, shown in Table 1. This structure contains the characteristics that should be considered to raise the research questions in a systematic literature review.

Table 1. Research questions as structured by the PICOC criteria.

\begin{tabular}{ll}
\hline Criteria & Description \\
\hline Population & Older adults \\
Intervention & Mobile technologies for health monitoring developed specifically for older adults \\
Comparison & No comparison \\
Outcome & Identify and analyze mobile technologies for health monitoring focused on older adults \\
Context & Health monitoring \\
\hline
\end{tabular}

Three research questions were defined, related to the understanding of the types of mobile technologies for monitoring the health of older adults, which of these technologies include self-reporting and data visualization, and which types of data have been recorded. Hence, the research questions guiding this research are the following ones:

- RQ1 Which types of mobile health technologies have been used to monitor older adults' health information?

- Do mobile health technologies for older adults include data visualization?

- Do mobile health technologies for older adults include self-reporting?

- RQ2 Which health information about older adults is usually monitored?

- RQ3 How are mobile health technologies for older adults evaluated?

\subsection{Search Terms}

We undertook systematic searches using keywords of publications between 2009 and 2019 in the ACM Digital Library database. The following keywords were used: ("mobile" OR "wearable" OR "sensor*") AND “*health" AND ("older" OR "senior" OR "elder*") in the publication titles, keywords, or abstracts. The asterisk operator $\left(^{*}\right)$ indicates that there may be more letters after the root word. In total, 189 articles were retrieved. 


\subsection{Inclusion/Exclusion Criteria}

We included studies if they met the following criteria: (1) involved independent older adults, (2) included mobile technologies to monitor health, (3) peer reviewed and obtained from a journal, conference, or workshop, (4) published between 2009 and 2019, and (5) published in English. Articles were excluded if they presented mobile health technology for older adults to be managed by caregivers, family or health experts or studies where there is only a design or proposal but no implementation and/or evaluation.

\subsection{Data Extraction and Synthesis}

The included articles were selected through two steps. First, two authors (GC and PR) independently reviewed the abstract and title of each of the retrieved sources and applied the inclusion/exclusion criteria. Publications with two votes to include or exclude were automatically included or excluded. Publications with differing votes were sent to a third reviewer $(\mathrm{VH})$, who analyzed it and determined whether the publication should be included or not. Then, two reviewers read the full text of ten randomly selected papers independently until there was consensus about which papers to include and exclude. They also extracted information separately. Several meetings were held to reach an agreement on the extracted information, adjust or merge labels, etc. The rest of the papers were divided and information was extracted by one reviewer.

\section{Results}

\subsection{Data Extraction and Synthesis}

In total, 189 references were identified from the ACM Digital Library database. After removal of duplicates, 140 publications remained. These were analyzed for abstract and title, and 91 publications were excluded because they did not meet the inclusion criteria. A total of 49 publications were evaluated for full text and 23 publications satisfied the aforementioned eligibility criteria and were included in the final review. Many articles were discarded because they did not present an evaluation of the proposed technology. The selection flow diagram for this study is presented in Figure 1.

Subsequently, the key details were extracted and synthesized from the 23 studies included in our systematic review. Several types of data were extracted from the studies: (1) demographics including the year of publication, country where the study took place, publication area, (2) type of technology including device location and monitored data, and (3) study design. More details are presented in the following sections.

\subsection{Characteristics of Included Studies}

The distribution of the included studies per year is shown in Figure 2. The number of studies noticeably increased in the past few years. Most of the reviewed articles were published in conferences $(16 / 23,69.6 \%)$ and only 4 of $23(17.4 \%)$ in journals. The rest of the studies were published in a workshop $(3 / 23,13 \%)$. Regarding the countries where the research was carried out, most were conducted in Europe $(9 / 23,39.1)$ and Latin America $(5 / 23,21.7 \%)$. The rest of the studies were conducted in North America $(4 / 23,17.4 \%)$, Asia $(4 / 23,17.4 \%)$ and Oceania $(1 / 23,4.3 \%)$. 

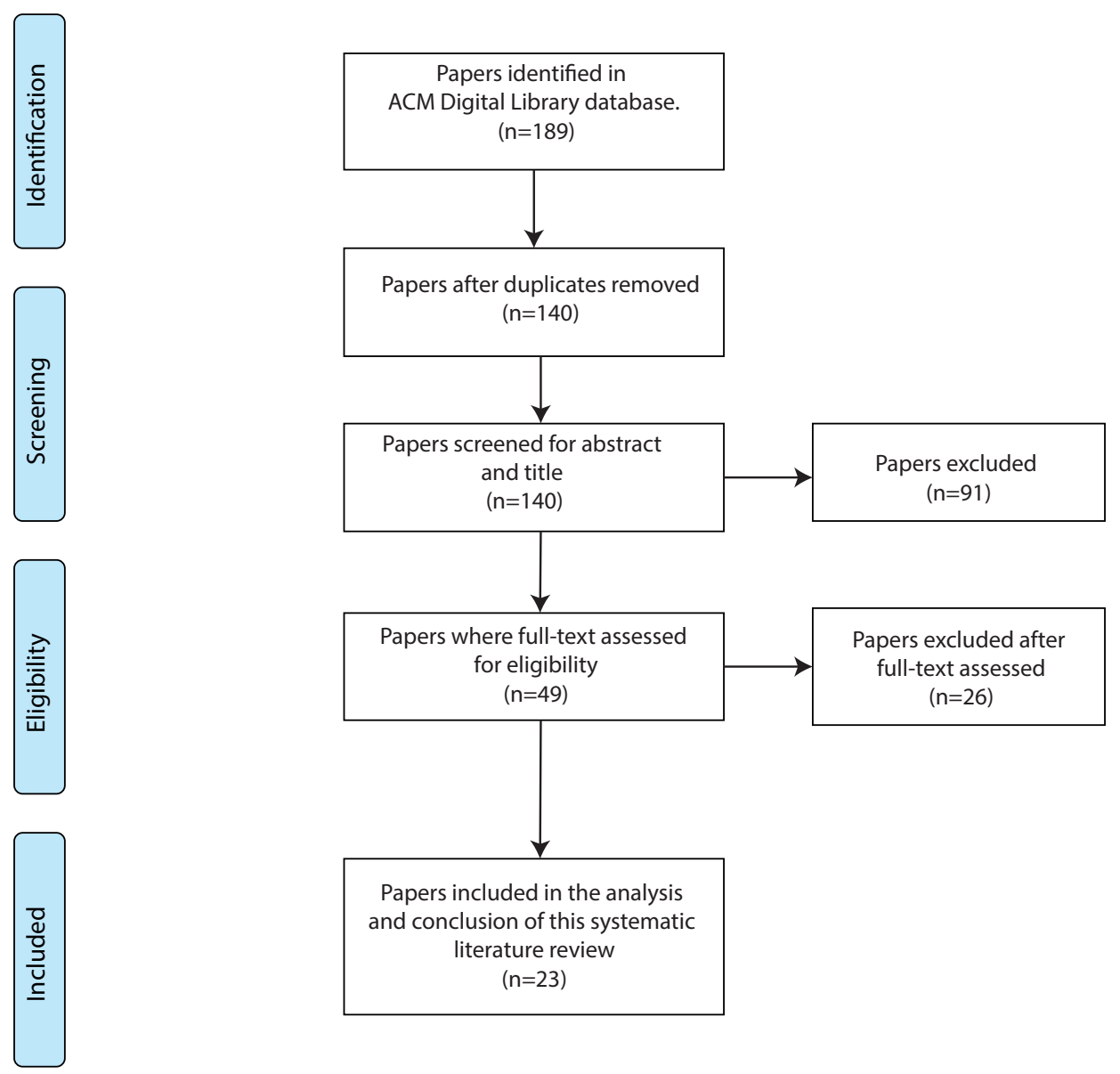

Figure 1. Systematic literature review flow diagram, following the PRISMA guidelines.

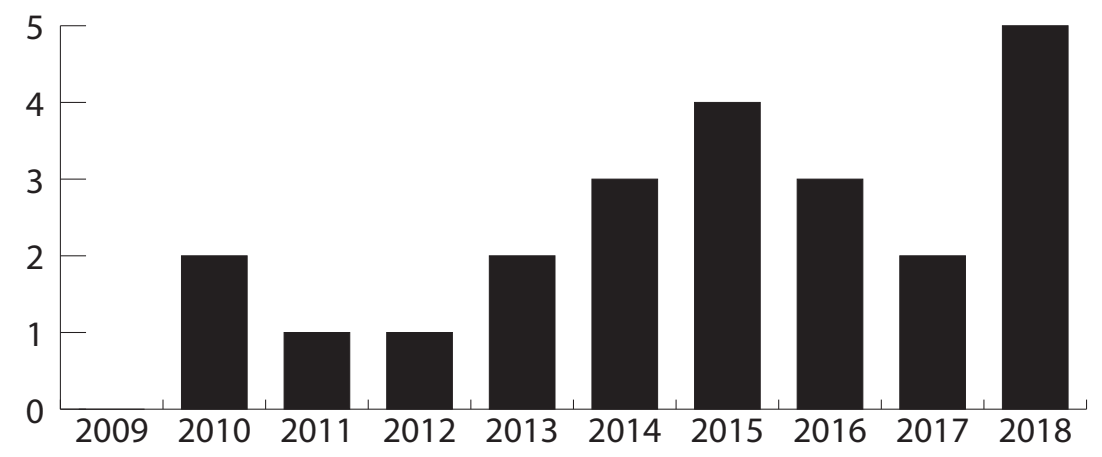

Figure 2. Frequency of publications per year.

The studies mostly focused on several specific problems: (1) detection of activities of daily living, (2) fall detection (3) pulmonary disease, (4) social interaction, (5) medication management, (6) chronic pain and (7) ambient assisted living (see Figure 3). The largest number of studies concerned the monitoring of daily activity (10 articles), which includes walking, physical activities, and body movement. Fall detection is the next highest category ( 5 articles); this situation is considered risky for older adults because it may affect health and wellness.

Next, we present the results for each of the research questions. 


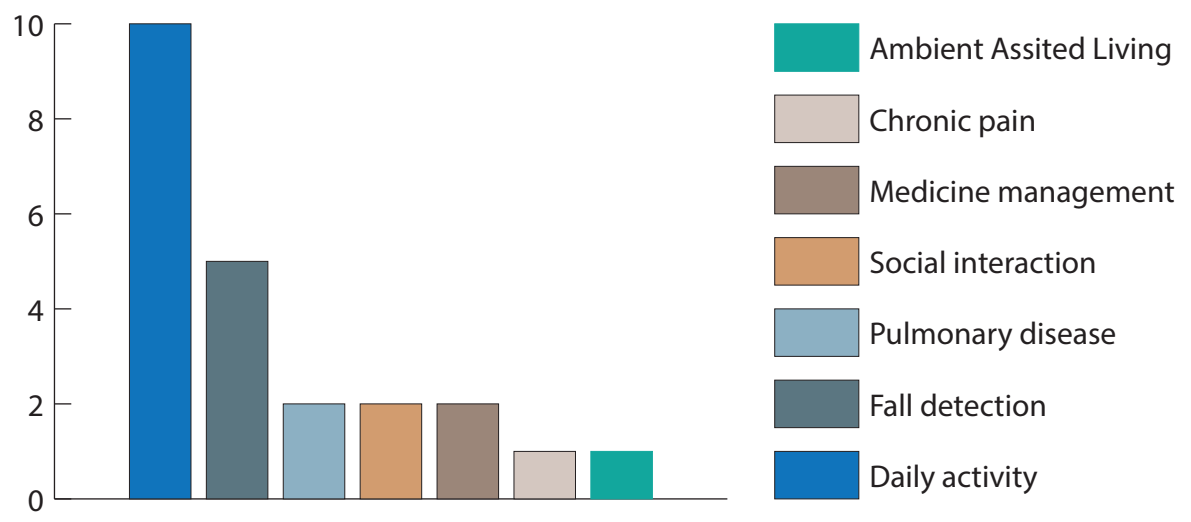

Figure 3. Number of publications for each of the targeted problems.

4.3. RQ1 Which Types of Mobile Health Technologies have been Used to Monitor Older Adults' Health Information?

We identified mobile technology that monitors the health of older adults through several types of devices: smartphones, smart bracelets, accelerometers, oximeters and heart rate sensors. For this analysis, we extracted the type of technology, where the device is placed on the body, and whether the proposed device or system includes self-reporting and/or data visualization (See Table 2). The most common type of mobile technology used to monitor older adults' health is a smart phone (13/31, $41.9 \%)$, followed by a smart bracelet $(7 / 31,22.5 \%)$ which includes smart watches and wristwatches. The accelerometer is the next most common technology $(6 / 31,19.3 \%)$. Oxygen and heart rate sensors are used less frequently $(3 / 31,9.6 \%$ and $2 / 31,6.4 \%$, respectively). Regarding location of technology, nine locations were reported. The most common location were the wrist $(25 \%)$ and waist $(18.8 \%)$. Out of the analyzed studies, $69.5 \%$ presented technology with data visualization and only $39 \%$ included self-reporting, out of which $87 \%$ were targeted to older adults.

\subsection{RQ2 Which Health Information about Older Adults is Usually Monitored?}

We found 12 different types of monitored data including position, acceleration, medical appointments, and heart rate (See Table 3). The most frequently collected data were acceleration, heart rate, position and oxygen level. Most research in this review uses acceleration data to detect gait speed [37], activity intensity [15], or tooth brushing [38]. Next was heart rate data: the collection of this information is a potentially viable option for individualized examination especially for older adults [30,39]. Position data is mainly used for the user's location [40,41], and this information can be complemented with acceleration data for assessing functional status and health [15]. Oxygen level is the next most frequently collected data. Providing a technology that can continually monitor an older person's physiological activity (i.e., pulse, oxygen) at regular intervals could detect diseases and other complications earlier [42,43]. Medication management concerns reminding older adults to take their medication with the appropriate frequency $[32,44]$. Finally, other studies focused on the collection of data on chronic pain, energy consumption, medical appointments or sleep patterns. 
Table 2. Mobile technology used to monitor the health of older adults $\mathrm{Y}=$ yes, blank = no.

\begin{tabular}{|c|c|c|c|c|c|c|c|c|}
\hline \multirow[t]{2}{*}{ Study } & \multicolumn{5}{|c|}{ Type of Technology } & \multirow[t]{2}{*}{ Location } & \multirow[t]{2}{*}{$\begin{array}{c}\text { Self- } \\
\text { Reporting }\end{array}$} & \multirow[t]{2}{*}{$\begin{array}{c}\text { Data } \\
\text { Visualization }\end{array}$} \\
\hline & $\begin{array}{l}\text { Smart } \\
\text { Phone }\end{array}$ & $\begin{array}{c}\text { Smart } \\
\text { Bracelet }\end{array}$ & $\begin{array}{l}\text { Accelero- } \\
\text { Meter }\end{array}$ & $\begin{array}{l}\text { Heart Rate } \\
\text { Sensor }\end{array}$ & Oximeter & & & \\
\hline [15] & $\mathrm{Y}$ & & & & & waist & Y & $\mathrm{Y}$ \\
\hline [40] & & & Y & & & $\begin{array}{l}\text { walker } \\
\text { trunk }\end{array}$ & & \\
\hline [37] & Y & $\mathrm{Y}$ & Y & & & wrist & & \\
\hline [42] & Y & & & & $\mathrm{Y}$ & $\begin{array}{l}\text { trunk } \\
\text { finger }\end{array}$ & & Y \\
\hline [22] & Y & & & & & waist & & Y \\
\hline [45] & Y & & & & & hand & & Y \\
\hline [46] & Y & & & & & pocket & $\mathrm{Y}$ & Y \\
\hline [47] & Y & & & & & waist & Y & Y \\
\hline [48] & Y & & & & & hand & Y & Y \\
\hline [27] & & Y & & & & wrist & Y & Y \\
\hline [30] & & Y & & & & wrist & & Y \\
\hline [38] & & $\mathrm{Y}$ & & & & wrist & Y & $\mathrm{Y}$ \\
\hline [49] & & $\mathrm{Y}$ & & & & wrist & & \\
\hline [50] & & & $\mathrm{Y}$ & & & chest & & \\
\hline [51] & & & Y & & & $\begin{array}{l}\text { trunk } \\
\text { waist }\end{array}$ & & \\
\hline [16] & & Y & & & & wrist & & Y \\
\hline [39] & Y & & & $\mathrm{Y}$ & Y & wheelchair & $\mathrm{Y}$ & Y \\
\hline [32] & Y & & & & & hand & $\mathrm{Y}$ & Y \\
\hline [44] & Y & & & & & hand & & Y \\
\hline [52] & & & Y & & & $\begin{array}{l}\text { chest } \\
\text { knee }\end{array}$ & & \\
\hline [41] & Y & Y & & & & $\begin{array}{l}\text { wrist } \\
\text { waist }\end{array}$ & Y & Y \\
\hline [53] & Y & & & & & $\begin{array}{l}\text { hand } \\
\text { pocket } \\
\text { chest }\end{array}$ & & \\
\hline [43] & & & Y & Y & Y & $\begin{array}{l}\text { wrist } \\
\text { finger }\end{array}$ & & Y \\
\hline
\end{tabular}

Table 3. Data monitored.

\begin{tabular}{|c|c|c|}
\hline Data Monitored & Study & Definition \\
\hline Position & {$[15,40,41,43]$} & Location on the map \\
\hline Activity time & [15] & Activity duration \\
\hline Acceleration & $\begin{array}{l}{[15,22,30,38,45,46]} \\
{[16,41,49-52]}\end{array}$ & $\begin{array}{l}\text { Change of velocity of an object } \\
\text { with respect to time }\end{array}$ \\
\hline Heart rate & {$[30,37,39,42,43]$} & Heartbeat counting \\
\hline Oxygen level & {$[37,42,43]$} & Oxygen saturation level \\
\hline Medical appointments & [48] & $\begin{array}{l}\text { Planning for a visit to a health care } \\
\text { professional }\end{array}$ \\
\hline Chronic pain & [27] & $\begin{array}{l}\text { Usually chronic pain is because } \\
\text { of an illness }\end{array}$ \\
\hline Emotions & [27] & Feelings in a certain context \\
\hline Sleep patterns & [30] & $\begin{array}{l}\text { Characteristics of sleep including } \\
\text { cycle, intensity, quality }\end{array}$ \\
\hline Pulse & {$[39,43]$} & Mechanical vibration of blood flow \\
\hline Medication management & {$[32,44]$} & $\begin{array}{l}\text { Regulation of the quantity } \\
\text { and frequency of medications }\end{array}$ \\
\hline Energy consumption & [41] & Amount of energy or power used \\
\hline
\end{tabular}

\subsection{RQ3 How Are Mobile Health Technologies for Older Adults Evaluated?}

The methodology used in each publication was analyzed. A quantitative methodology was applied in 16 of 23 studies (82.6\%), 2 used qualitative methodology (8.6\%), and 2 (8.6\%) applied mixed methods. Participants' age ranged from 11 to 94 years with 7 of 23 studies (30.4\%) focused only on older adults. In terms of participant health characteristics, 3 articles $[30,32,47]$ targeted older adults 
that did not need intensive medical attention and $3[27,37,42]$ looked at those with a specific condition (pulmonary disease, fibromyalgia, or pain). Sample sizes ranged from 3 to 42 participants with five of the studies including ten individuals or less. Most studies with older adults lasted a short time: only 2 studies used more than three weeks for the evaluation [32]. In most cases, studies were small and operated as feasibility studies or pilot investigations, offering limited knowledge concerning the impact of full-scale implementation [32]. Researchers recognize the need for full-scale trials and information on best practices for the design, implementation and evaluation of mobile technologies for older adults [44].

\section{Discussion}

We reviewed the past 11 years of literature related to health monitoring, as published in the ACM Digital Library, using a systematic literature review methodology. We acknowledge some limitations in our study. Since the search was done at the end of May 2019, several papers published after that date were not included. Furthermore, we only used one specific database which only has papers in English. We found an increasing number of papers, suggesting that this area is increasingly attracting the attention of academics, which means that the search in the ACM Digital Library should in the future be complemented with additional sources.

The type of technology most used to monitor the health of older people is the smartphone, which incorporates sensors such as accelerometers, GPS or applications that can facilitate the health management of this population in the detection of daily activities [45,53], detection of falls or fragility [47]. In fact, mobile phones are the technology most used by older adults for browsing or consulting health information [4].

During the period under review, the mobile phone is the most frequently used device for monitoring the health of older people. However, from 2014 on, wearable devices such as health trackers (e.g., Fitbit) and smartwatches have been used to monitor the health of older adults $[27,37,43]$.

It was not surprising to find several studies where the evaluation participants were not older adults. In our experience, it is not an easy task to recruit older adults for studies, because some of them fear technology. Additionally, and as we mentioned in Section 4.1, we found several articles where the authors proposed new technologies but these were not evaluated with people or real data. Also, the focus of the publications has changed through the years. At the beginning of the period covered by our review, there were more publications about proposals and design of mobile health technology. In the past four years, publications more often reported on the evaluation of such technologies. However, the sample size of these evaluations is still small, and the duration is short. Moreover, in specific type of interventions such as preventing falls in older adults, the period of time for obtaining results should be over six months [54].

The loss of autonomy and independence while carrying out activities of daily living and falls are among the top concerns of older adults, because they could lead them to have functional limitations $[55,56]$. The results of our SLR agree with this, as most of the articles that were selected are related to these two topics, as shown in Figure 3.

Several systematic reviews related to technology for health management for the elderly have been conducted. Some studies have considered publications in a short time span (e.g., [57]), while others have considered specific problem areas such as pain [58], cardiovascular disease [14], or balance and fall risk assessments [59]. In addition, some research has focused on interventions that use mobile technology to alter physical activity, sedentary behavior, and sleep in older adults [60]. The evidence collected in previous research is limited to technologies targeting a specific condition or promoting activities as contrast to the present work in which we focus on technology for health management in general. 


\section{Conclusions and Future Work}

This study identified several mobile technologies that are used to monitor older adults, with the most common being the smartphone. We also identified that out of the proposed technologies, $69.5 \%$ include data visualization and only $36 \%$ include self-report, providing an opportunity for researchers to create technology that allows older adults to complement sensor data with subjective information. We have provided an outline of the monitored data that may help both researchers and practitioners understand which information to monitor when designing technologies for older adults, finding that the most commonly monitored data are acceleration, heart rate and position.

The review found that often (in 7 out of 23 studies), technology designed for older users is evaluated using younger adults as participants. We posit that if the the target of mobile technologies solutions are older adults it is imperative to be working with these end-users when designing, implementing, and evaluating such solutions.

The review presented in this paper is based on a systematic search of mobile technologies available in the existing literature from only one scientific online database. As future work, we will expand our literature review by considering additional digital libraries to widen the scope of our literature review and take into account a greater number of studies from other areas.

Funding: This paper was partly funded by CONICYT/FONDECYT 1181162 and CONICYT PFCHA/ DOCTORADO NACIONAL/2018 - 21180784.

Conflicts of Interest: The authors declare no conflict of interest.

\section{References}

1. Katzmarzyk, P.T.; Mason, C. The physical activity transition. J. Phys. Act. Health 2009, 6, 269-280.

2. Kim, B.Y.; Lee, J. Smart devices for older adults managing chronic disease: A scoping review. JMIR MHealth UHealth 2017, 5, e69.

3. Joe, J.; Demiris, G. Older adults and mobile phones for health: A review. J. Biomed. Inform. 2013, 46, 947-954.

4. Kuerbis, A.; Mulliken, A.; Muench, F.; Moore, A.A.; Gardner, D. Older adults and mobile technology: Factors that enhance and inhibit utilization in the context of behavioral health. Ment. Health Addict. Res. 2017, 2,1-11.

5. Patel, K.V.; Guralnik, J.M.; Dansie, E.J.; Turk, D.C. Prevalence and impact of pain among older adults in the United States: Findings from the 2011 National Health and Aging Trends Study. Pain 2013, 154, 2649-2657.

6. Stedmon, A.W.; Howells, H.; Wilson, J.R.; Dianat, I. Ergonomics/human factors needs of an ageing workforce in the manufacturing sector. Health Promot. Perspect. 2012, 2, 112.

7. OECD. Skills Matter: Further Results from the Survey of Adult Skills. In series: OECD Skills Studies, 2016. Available online: https://www.oecd.org/skills/piaac/Skills_Matter_Further_Results_from_the_Survey_ of_Adult_Skills.pdf (accessed on 1 July 2019).

8. Bhattarai, P.; Phillips, J.L. The role of digital health technologies in management of pain in older people: An integrative review. Arch. Gerontol. Geriatr. 2017, 68, 14-24.

9. Van Deursen, A.J.; Helsper, E.J. A nuanced understanding of Internet use and non-use among the elderly. Eur. J. Commun. 2015, 30, 171-187.

10. Harjumaa, M.; Isomursu, M. Field Work With Older Users-Challenges in Design and Evaluation of Information Systems. Electron. J. Inf. Syst. Eval. 2012, 15, 50-62.

11. dos Santos, T.D.; Santana, V.F.D. Computer Anxiety and Interaction: A Systematic Review. In Proceedings of the Internet of Accessible Things, Lyon, France, 23-25 April 2018; pp. 18:1-18:10, doi:10.1145/3192714.3192825.

12. Holgersson, J.; Söderström, E. Bridging the gap: Exploring elderly citizens' perceptions of digital exclusion. In Proceedings of the 27th European Conference on Information Systems (ECIS), Stockholm \& Uppsala, Sweden, 8-14 June 2019.

13. Yin, D.; Chen, K. The essential mechanisms of aging: Irreparable damage accumulation of biochemical side-reactions. Exp. Gerontol. 2005, 40, 455-465. 
14. Searcy, R.P.; Summapund, J.; Estrin, D.; Pollak, J.P.; Schoenthaler, A.; Troxel, A.B.; Dodson, J.A. Mobile Health Technologies for Older Adults with Cardiovascular Disease: Current Evidence and Future Directions. Curr. Geriatr. Rep. 2019, 8, 31-42.

15. Castro, L.A.; Favela, J.; Quintana, E.; Perez, M. Behavioral data gathering for assessing functional status and health in older adults using mobile phones. Pers. Ubiquitous Comput. 2015, 19, 379-391.

16. Matthies, D.J.; Haescher, M.; Nanayakkara, S.; Bieber, G. Step Detection for Rollator Users with Smartwatches. In Proceedings of the Symposium on Spatial User Interaction, Berlin, Germany, 13-14 October 2018; pp. 163-167.

17. Cook, E.J.; Randhawa, G.; Sharp, C.; Ali, N.; Guppy, A.; Barton, G.; Bateman, A.; Crawford-White, J. Exploring the factors that influence the decision to adopt and engage with an integrated assistive telehealth and telecare service in Cambridgeshire, UK: A nested qualitative study of patient 'users' and 'non-users'. BMC Health Serv. Res. 2016, 16, 137.

18. Gokalp, H.; Clarke, M. Monitoring activities of daily living of the elderly and the potential for its use in telecare and telehealth: A review. Telemed. E-Health 2013, 19, 910-923.

19. Cajamarca, G.; Rodríguez, I.; Herskovic, V.; Campos, M.; Riofrío, J. StraightenUp+: Monitoring of Posture during Daily Activities for Older Persons Using Wearable Sensors. Sensors 2018, 18, 3409.

20. Villalba, E.; Salvi, D.; Ottaviano, M.; Peinado, I.; Arredondo, M.T.; Akay, A. Wearable and mobile system to manage remotely heart failure. IEEE Trans. Inf. Technol. Biomed. 2009, 13, 990-996.

21. Simpson, L.; Maharaj, M.M.; Mobbs, R.J. The role of wearables in spinal posture analysis: A systematic review. BMC Musculoskelet. Disord. 2019, 20, 55.

22. Dai, J.; Bai, X.; Yang, Z.; Shen, Z.; Xuan, D. Mobile phone-based pervasive fall detection. Pers. Ubiquitous Comput. 2010, 14, 633-643, doi:10.1007/s00779-010-0292-x.

23. Bush, T.L.; Miller, S.R.; Golden, A.L.; Hale, W.E. Self-report and medical record report agreement of selected medical conditions in the elderly. Am. J. Public Health 1989, 79, 1554-1556.

24. Schootman, M.; Jeffe, D.B.; West, M.M.; Aft, R. Self-report by elderly breast cancer patients was an acceptable alternative to surveillance, epidemiology, and end results (SEER) abstract data. J. Clin. Epidemiol. 2005, $58,1316-1319$.

25. Skinner, K.M.; Miller, D.R.; Lincoln, E.; Lee, A.; Kazis, L.E. Concordance between respondent self-reports and medical records for chronic conditions: Experience from the Veterans Health Study. J. Ambul. Care Manag. 2005, 28, 102-110.

26. Rozario, P.A.; Morrow-Howell, N.; Proctor, E. Comparing the congruency of self-report and provider records of depressed elders' service use by provider type. Med. Care 2004, 42, 952-959.

27. Rodriguez, I.; Herskovic, V.; Fuentes, C.; Campos, M. B-ePain: A wearable interface to self-report pain and emotions. In Proceedings of the 2016 ACM International Joint Conference on Pervasive and Ubiquitous Computing: Adjunct, Heidelberg, Germany, 12-16 September 2016; pp. 1120-1125.

28. Hawthorn, D. Possible implications of aging for interface designers. Interact. Comput. 2000, 12, 507-528.

29. Le, T.; Chi, N.C.; Chaudhuri, S.; Thompson, H.J.; Demiris, G. Understanding older adult use of data visualizations as a resource for maintaining health and wellness. J. Appl. Gerontol. 2018, 37, 922-939.

30. Hu, R.; Pham, H.; Buluschek, P.; Gatica-Perez, D. Elderly people living alone: Detecting home visits with ambient and wearable sensing. In Proceedings of the 2nd International Workshop on Multimedia for Personal Health and Health Care, Mountain View, CA, USA, 23 October 2017; pp. 85-88.

31. Macdonald, A.S.; Loudon, D.; Rowe, P.J.; Samuel, D.; Hood, V.; Nicol, A.C.; Grealy, M.A.; Conway, B.A. Towards a design tool for visualizing the functional demand placed on older adults by everyday living tasks. Univers. Access Inf. Soc. 2007, 6, 137-144.

32. Hamid, A.; Sym, F.P. Designing for patient-centred factors in medical adherence technology. In Proceedings of the 6th International Conference on Rehabilitation Engineering \& Assistive Technology, Tampines, Singapore, 24-26 July 2012; p. 40.

33. Skubic, M.; Guevara, R.D.; Rantz, M. Automated health alerts using in-home sensor data for embedded health assessment. IEEE J. Transl. Eng. Health Med. 2015, 3, 1-11.

34. Reeder, B.; Chung, J.; Le, T.; Thompson, H.; Demiris, G. Assessing older adults' perceptions of sensor data and designing visual displays for ambient environments. Methods Inf. Med. 2014, 53, 152-159.

35. Le, T.; Reeder, B.; Thompson, H.; Demiris, G. Health providers' perceptions of novel approaches to visualizing integrated health information. Methods Inf. Med. 2013, 52, 250-258. 
36. Kitchenham, B.; Charters, S. Guidelines for Performing Systematic Literature Reviews in Software Engineering; Technical Report EBSE 2007-01; Keele University and Durham University: Keele, UK, 2007.

37. Juen, J.; Cheng, Q.; Schatz, B. Towards a natural walking monitor for pulmonary patients using simple smart phones. In Proceedings of the 5th ACM Conference on Bioinformatics, Computational Biology, and Health Informatics, Newport Beach, CA, USA, 20-23 September 2014; pp. 53-62.

38. Cherian, J.; Rajanna, V.; Goldberg, D.; Hammond, T. Did you remember to brush?: A noninvasive wearable approach to recognizing brushing teeth for elderly care. In Proceedings of the 11th EAI International Conference on Pervasive Computing Technologies for Healthcare, Barcelona, Spain, 23-26 May 2017; pp. $48-57$.

39. Wong, S.F.; Hoi, W.K.; Wan, I.K. Advanced Smart Wheelchair Design in Enhancing Quality of Life for Elder and Handicapped People. In Proceedings of the 4th International Conference on Industrial and Business Engineering, Macau, Macao, 24-26 October 2018; pp. 203-210.

40. Ojeda, M.; Cortés, A.; Béjar, J.; Cortés, U. Automatic classification of gait patterns using a smart rollator and the BOSS model. In Proceedings of the 11th PErvasive Technologies Related to Assistive Environments Conference, Corfu, Greece, 26-29 June 2018; pp. 384-390.

41. Nakagawa, E.; Moriya, K.; Suwa, H.; Fujimoto, M.; Arakawa, Y.; Hatta, T.; Miwa, S.; Yasumoto, K. Investigating recognition accuracy improvement by adding user's acceleration data to location and power consumption-based in-home activity recognition system. In Proceedings of the Adjunct Proceedings of the 13th International Conference on Mobile and Ubiquitous Systems: Computing Networking and Services, Hiroshima, Japan, 28 November-1 December 2016; pp. 100-105.

42. Cheng, Q.; Juen, J.; Schatz, B.R. Using mobile phones to simulate pulse oximeters: Gait analysis predicts oxygen saturation. In Proceedings of the 5th ACM Conference on Bioinformatics, Computational Biology, and Health Informatics, Newport Beach, CA, USA, 20-23 September 2014; pp. 331-340.

43. Nazário, D.C.; de Andrade, A.; Borges, L.; Ramos, W.R.; Todesco, J.L.; Dantas, M.A.R. An Enhanced Quality of Context Evaluating Approach in the e-Health Sensor Platform. In Proceedings of the 11th ACM Symposium on QoS and Security for Wireless and Mobile Networks, Cancun, Mexico, 2-6 November 2015; pp. 1-7.

44. Rodríguez, M.D.; García-Vázquez, J.P.; Andrade, Á.G. Design dimensions of ambient information systems to facilitate the development of AAL environments. In Proceedings of the 4th International Conference on PErvasive Technologies Related to Assistive Environments, Heraklion, Crete, Greece, 25-27 May 2011; p. 4.

45. Sunwoo, J.; Yuen, W.; Lutteroth, C.; Wünsche, B. Mobile games for elderly healthcare. In Proceedings of the 11th International Conference of the NZ Chapter of the ACM Special Interest Group on Human-Computer Interaction, Auckland, New Zealand, 8-9 July 2010; pp. 73-76.

46. Martín, H.; Bernardos, A.M.; Iglesias, J.; Casar, J.R. Activity logging using lightweight classification techniques in mobile devices. Pers. Ubiquitous Comput. 2013, 17, 675-695.

47. Fontecha, J.; Navarro, F.J.; Hervás, R.; Bravo, J. Elderly frailty detection by using accelerometer-enabled smartphones and clinical information records. Pers. Ubiquitous Comput. 2013, 17, 1073-1083.

48. Monteiro, J.M.; Lopes, C.T. HealthTalks-A Mobile App to Improve Health Communication and Personal Information Management. In Proceedings of the 2018 Conference on Human Information Interaction \& Retrieval, New Brunswick, NJ, USA, 11-15 March 2018; pp. 329-332.

49. Bieber, G.; Haescher, M.; Hanschmann, P.; Matthies, D.J. Exploring Accelerometer-based Step Detection By using a Wheeled Walking Frame. In Proceedings of the 5th international Workshop on Sensor-based Activity Recognition and Interaction, Berlin, Germany, 20-21 September 2018; p. 8.

50. Fourlas, G.K.; Maglogiannis, I. Human movement detection using attitude and heading reference system. In Proceedings of the 7th International Conference on PErvasive Technologies Related to Assistive Environments, Rhodes, Greece, 27-30 May 2014; p. 30.

51. Alemdar, H.Ö.; Yavuz, G.R.; Özen, M.O.; Kara, Y.E.; Incel, Ö.D.; Akarun, L.; Ersoy, C. Multi-modal fall detection within the WeCare framework. In Proceedings of the 9th ACM/IEEE International Conference on Information Processing in Sensor Networks, Stockholm, Sweden, 12-16 April 2010; pp. 436-437.

52. Ojetola, O.; Gaura, E.; Brusey, J. Data set for fall events and daily activities from inertial sensors. In Proceedings of the 6th ACM multimedia systems conference, Portland, OR, USA, 18-20 March 2015; pp. 243-248. 
53. Fareed, U. Smartphone sensor fusion based activity recognition system for elderly healthcare. In Proceedings of the 2015 Workshop on Pervasive Wireless Healthcare, Hangzhou, China, 22 June 2015; pp. 29-34.

54. Delbaere, K.; Valenzuela, T.; Woodbury, A.; Davies, T.A.; Yeong, J.J.; Steffens, D.; Miles, L.; Pickett, L.; Zijlstra, G.A.R.; Clemson, L.; et al. Evaluating the effectiveness of a home-based exercise programme delivered through a tablet computer for preventing falls in older community-dwelling people over 2 years: Study protocol for the Standing Tall randomised controlled trial. BMJ Open 2015, 5, e009173.

55. Arkkukangas, M.; Söderlund, A.; Eriksson, S.; Johansson, A.C. Fall Preventive Exercise With or Without Behavior Change Support for Community-Dwelling Older Adults: A Randomized Controlled Trial With Short-Term Follow-up. J. Geriatr. Phys. Ther. 2019, 42, 9-17.

56. Lau, K.M.; Parikh, M.; Harvey, D.J.; Huang, C.J.; Farias, S.T. Early Cognitively Based Functional Limitations Predict Loss of Independence in Instrumental Activities of Daily Living in Older Adults. J. Int. Neuropsychol. Soc. 2015, 21, 688-698.

57. Kruse, C.S.; Mileski, M.; Moreno, J. Mobile health solutions for the aging population: A systematic narrative analysis. J. Telemed. Telecare 2017, 23, 439-451.

58. Rodríguez, I.; Herskovic, V.; Gerea, C.; Fuentes, C.; Rossel, P.O.; Marques, M.; Campos, M. Understanding Monitoring Technologies for Adults With Pain: Systematic Literature Review. J. Med Internet Res. 2017, 19, e364.

59. Roeing, K.L.; Hsieh, K.L.; Sosnoff, J.J. A systematic review of balance and fall risk assessments with mobile phone technology. Arch. Gerontol. Geriatr. 2017, 73, 222-226.

60. Elavsky, S.; Knapova, L.; Klocek, A.; Smahel, D. Mobile Health Interventions for Physical Activity, Sedentary Behavior, and Sleep in Adults Aged 50 Years and Older: A Systematic Literature Review. J. Aging Phys. Act. 2019, 27, 565-593.

(C) 2019 by the authors. Licensee MDPI, Basel, Switzerland. This article is an open access article distributed under the terms and conditions of the Creative Commons Attribution (CC BY) license (http://creativecommons.org/licenses/by/4.0/). 